\title{
The effects of exposure to a protein- and tryptophan-deficient diet upon taste-aversion learning
}

\author{
STEPHEN F. DAVIS, SCOTT A. BAILEY, MECHELLE A. MAYLEBEN, \\ BOBBY L. FREEMAN, and GREG L. PAGE \\ Emporia State University, Emporia, Kansas
}

\begin{abstract}
One group of 10 rats was maintained on a protein- and tryptophan-deficient diet of corn grits for the 50 days that followed weaning. During the subsequent 50 days, these animals were provided the normal diet of laboratory chow (diet reversal). At the conclusion of the diet-reversal phase, these animals and a comparable group of normally reared littermates received a pairing of novel saccharin and lithium chloride. Exposure to the experimental diet significantly retarded growth, while returning the deprived animals to the normal diet led to weight gain and growth. Reflecting the lack of lasting deficits produced by the experimental diet, comparable taste aversions were displayed by both groups.
\end{abstract}

An examination of the literature relating the effects of protein-deficient diets to learning deficits yields an inconsistent pattern of results. For example, correlational studies of human subjects (e.g., Cravioto \& Robles, 1965; Kaplan, 1972; Winick, 1976) reported a positive relationship between dietary exposure and mental deficiency.

On the other hand, the results of more highly controlled laboratory studies have not been as consistent. Although Cowley and Griesel (1959, 1963) observed learning deficits in deprived rats tested in the Hebb-Williams maze and Caldwell and Churchill (1967) found that deprived animals were inferior to controls in the pole-jump avoidance task, not all results have been positive. For example, Remley, Armstrong, Gilman, and Mercer (1980) found that rats raised on a protein- and tryptophandeficient diet of corn grits did not differ in the acquisition of two-way active avoidance from rats raised on a normal diet. Likewise, Becker, Davis, Grover, and Erickson (1990) reported that protein- and tryptophan-deficient rats did not differ from normally reared littermates in mastering the Hampton Court maze.

While the question of diminished cognitive capacity awaits further experimental attention, growth-related effects are more consistent and clearly delineated. For example, Remley et al. (1980) reported that even though weight differences did not exist at 30 days of age, pronounced differences had developed by the time their rat subjects were 60 days old. These differences persisted and were even exacerbated by 90 days of age.

By replicating these basic findings and also demonstrating that (1) sexual dimorphism was a nonsignificant ef-

Portions of this paper were presented at the 1990 meeting of the Southern Society for Philosophy and Psychology. Requests for reprints may be addressed to Stephen F. Davis, Department of Psychology, Emporia State University, Emporia, KS 66801. fect in grits-exposed rats by 75 days of age, and (2) even more dramatic effects were produced by placing nursing dams on the experimental diet coincident with the birth of the pups, Becker, Davis, Grover, and Erickson (1989) extended the Remley et al. (1980) data. Without question, the protein- and tryptophan-deficient grits diet produces animals that, at maturity, differ significantly from normally reared littermates.

The finding that this growth deficit can be reversed is noteworthy. For example, Becker et al. (1989) reported increasing weight gains for rats shifted from the grits diet to normal laboratory chow at 75 days of age. At this point, the normal males weighed 4.63 times more than the gritsfed males, and the normal females weighed 3.16 times more than the grits-fed females. By the time the animals were 183 days old, the weight differential had decreased to 1.77 for males and .24 for females. Thus, it should be possible to implement this dietary deficiency, reverse these conditions, and then evaluate any long-term effects that may have been produced. This procedure would allow one to test animals under more comparable states and would avoid potential problems, such as trying to equate motivational states between normal animals and deficient animals weighing three to four times less than normally reared littermates.

The conditioned taste aversion, a basic, classical conditioning paradigm, was selected for use in the present experiment. Research in this area (e.g., Best, 1975; Garcia, Hankins, \& Rusiniak, 1974; Kalat, 1974) has repeatedly demonstrated that the pairing of a novel taste (e.g., saccharin) with a toxin (e.g., lithium chloride) results in the development of a strong and lasting aversion to the novel taste. Through the use of the sensitive two-bottle preference test (Dragoin, McCleary, \& McCleary, 1971), it should be possible to ascertain differential effects (1) in the acquisition and retention of 
this response, and (2) in resistance to extinction of the aversion. To accomplish these goals, two groups of rats were exposed to the grits and normal diets, respectively, for the 50 days following weaning. For the ensuing 50 days, the normal diet was administered to both groups. All subjects received taste-aversion conditioning at 121 days of age. Three preference sessions were administered prior to home cage extinction of the aversive flavor. A final preference test concluded the experiment.

\section{METHOD}

\section{Subjects and Apparatus}

Two litters of Holtzman-derived rats $(N=20)$, born in the Emporia State University vivarium, served as subjects. When the pups were 1 day old, they were placed in a common holding tank and randomly reassigned to one of two equal groups $(n=10)$. In turn, each group was randomly assigned to one of the nursing dams. All pups were housed in a 10-gallon aquarium with the nursing dam until weaning (21 days). At this time, all subjects were transferred to individual wire-mesh cages. All testing took place in the home cage.

\section{Procedure}

At weaning, the subjects were randomly assigned to one of two equalsized groups $(n=10)$. For the next 50 days, until the animals were 71 days old, Group Grits was raised on a diet consisting exclusively of free access to oven-dried cakes of Quaker Instant Grits. ${ }^{1}$ The grits cakes employed during this grits-exposure phase were prepared by mixing $50 \mathrm{ml}$ of tap water per $226.8 \mathrm{~g}$ of Quaker Instant Grits. This mixture was placed on a cookie sheet and baked at $325^{\circ}$ for $1 \mathrm{~h}$. Then it was allowed to $\mathrm{cool}$ and was cut into $.60-\mathrm{cm}$ squares. These squares were baked at $325^{\circ}$ for an additional $1 \frac{1}{2} \mathrm{~h}$ or until they were thoroughly dry. During this same period, Group Normal consumed the standard diet of Purina Laboratory Chow.

For the subsequent 50 days (diet-reversal phase), the Grits animals were switched to the standard laboratory chow diet. Thus, both groups were maintained on the nondeficient normal diet from 71 to 121 days of age. Water was freely available to all animals during the grits-exposure and diet-reversal phases.

The experiment proper, begun when the animals were 121 days old, may be summarized as follows. On the 4 days prior to conditioning, all animals were habituated to the 23.75 -h water-deprivation regimen. A water-consumption baseline was calculated by allowing each subject 15-min access to water on these days. Water consumption was recorded to the nearest $.50 \mathrm{ml}$. On the next day, all subjects received taste-aversion conditioning to a novel saccharin flavor. More specifically, each subject was allowed 15 -min access to a $.15 \%(w / v)$ solution of sodium saccharin. Following this exposure, an intraperitoneal injection of lithium chloride (.30M at $.12 \%$ body weight) was administered to induce toxicosis.

Preference Test 1 was administered $24 \mathrm{~h}$ following conditioning. On this and all subsequent preference tests, each subject received simultaneous access to saccharin and plain tap water for $15 \mathrm{~min}$.

Following 18 days of free-access to water, water deprivation was reinstated and a daily consumption baseline determined. Three weeks following Preference Test 1 , Preference Session 2 was begun. This session consisted of four daily $15-\mathrm{min}$ preference tests. Preference Session 3, which was conducted in the same manner as Preference Session 2, was begun 3 weeks later.

A 4-day saccharin-extinction phase was begun $24 \mathrm{~h}$ following the completion of Preference Session 3. During this phase, all animals were allowed access to the saccharin solution for $15 \mathrm{~min}$ daily. A single preference test (Preference Test 4 ) was conducted $24 \mathrm{~h}$ following the completion of saccharin extinction.

During experimental testing, all animals were allowed free access to Purina Laboratory Chow. All fluids were presented in 50-ml graduated centrifuge tubes with spill-resistant sippers. All animals were weighed at weaning and every week thereafter.

\section{RESULTS}

Analysis of the weight data for the males during the 50-day grits-exposure phase (Weeks 1-7) yielded significance for the groups $[F(1,12)=27.32, p<.01]$, weeks $[F(6,72)=4.57, p<.01]$, and groups $\times$ weeks $[F(6,72)=3.36, p<.01]$ effects. Subsequent NewmanKeuls tests indicated that the weights of the Normal males were significantly greater than those of the Grits males by Week $2(p<.01)$. This significant difference persisted for the duration of the grits-exposure phase. Analysis of the weight data for the female animals yielded a similar pattern of results. The groups $[F(1,3)=63.24$, $p<.01]$, weeks $[F(6,18)=8.68, p<.01]$, and groups $\times$ weeks $[F(6,18)=6.11, p<.01]$ effects achieved significance. Newman-Keuls tests indicated that the Normal females weighed significantly more than the Grits females by Week $3(p<.01)$. These differences also persisted throughout the duration of the grits-exposure phase.

Analysis of the diet-reversal data (Weeks 8-19) also yielded significance for the groups [males, $F(1,12)=$ $10.77, p<.01$; females, $F(1,3)=16.01, p<.05$ ], weeks [males, $F(11,132)=4.51, p<.01$; females $F(11,33)=7.72, p<.01$ ] , and groups $\times$ weeks [females, $F(11,33)=4.23, p<.01]$ effects. Newman-Keuls tests indicated that the two groups of female animals had ceased to differ reliably by Week 14 . While the Grits males gained an appreciable amount of weight, they remained significantly lighter than the Normal males until the conclusion of the experiment $(p<.05)$. Mean weights (in grams) for the male and female Grits and Normal animals

Table 1

Mean Weights (g) for the Male and Female Animals during the Grits-Exposure and Diet-Reversal Phases

\begin{tabular}{|c|c|c|c|c|}
\hline \multirow[b]{2}{*}{ Weeks } & \multicolumn{2}{|c|}{ Males } & \multicolumn{2}{|c|}{ Females } \\
\hline & Normal & Grits & Normal & Grits \\
\hline \multicolumn{5}{|c|}{ Grits Exposure } \\
\hline 1 & 145.64 & 93.58 & 128.20 & 83.50 \\
\hline 2 & 210.67 & 94.21 & 170.60 & 85.80 \\
\hline 3 & 268.26 & 92.47 & 202.80 & 82.30 \\
\hline 4 & 328.88 & 90.74 & 231.36 & 81.35 \\
\hline 5 & 368.87 & 92.01 & 250.86 & 82.95 \\
\hline 6 & 400.97 & 91.37 & 267.06 & 74.85 \\
\hline 7 & 419.27 & 95.51 & 278.50 & 83.45 \\
\hline \multicolumn{5}{|c|}{ Diet Reversal } \\
\hline 1 & 449.00 & 147.84 & 291.60 & 132.85 \\
\hline 2 & 475.57 & 229.57 & 304.80 & 205.40 \\
\hline 3 & 507.37 & 310.02 & 321.93 & 228.15 \\
\hline 4 & 512.21 & 358.01 & 329.06 & 218.00 \\
\hline 5 & 529.56 & 374.74 & 333.23 & 217.30 \\
\hline 6 & 546.20 & 416.55 & 345.10 & 258.25 \\
\hline 7 & 557.22 & 439.71 & 356.46 & 280.65 \\
\hline 8 & 545.34 & 446.60 & 348.16 & 290.70 \\
\hline 9 & 574.40 & 470.58 & 357.23 & 307.50 \\
\hline 10 & 590.61 & 504.85 & 368.53 & 336.55 \\
\hline 11 & 590.25 & 513.27 & 363.56 & 337.85 \\
\hline 12 & 614.60 & 536.41 & 378.86 & 344.15 \\
\hline
\end{tabular}




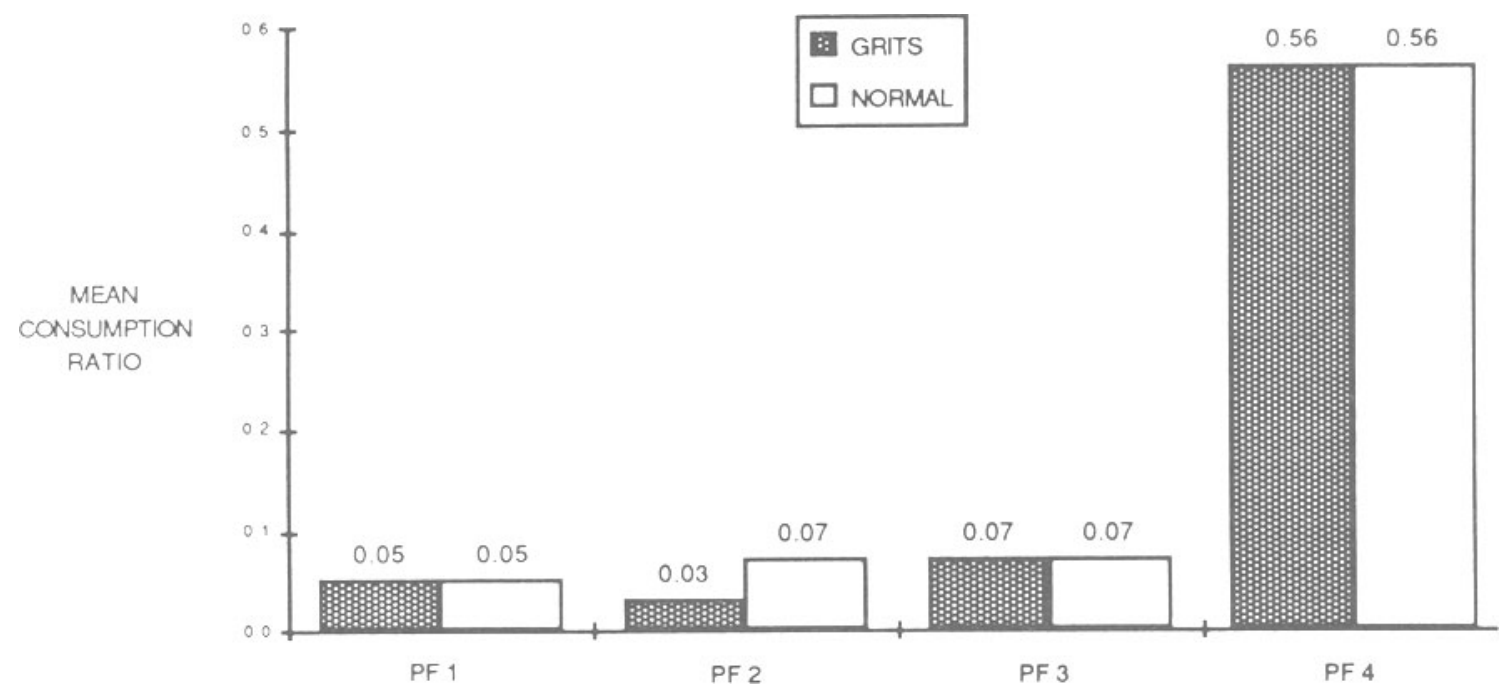

Figure 1. Mean consumption ratios (saccharin/saccharin + water) for the Grits and Normal animals on Preference Test 1 , the first day of Preference Sessions 2 and 3, and Preference Test 4. Ratios below .50 reflect a saccharin aversion; those above .50 reflect a saccharin preference.

during the grits-exposure and diet-reversal phases are shown in Table 1 .

As preliminary analyses failed to yield significant gender effects, the data from the preference tests were blocked over gender within the Normal and Grits groups. Since analyses of the baseline consumption data recorded prior to Preference Sessions 1, 2, and 3 failed to yield significant between-group effects [largest $F(1,17)=.158$ ], the groups were deemed equivalent prior to the start of these three sessions.

Figure 1 presents the results of the two-bottle tests for the four preference sessions. To facilitate comparisons, only the first test day of Preference Sessions 2 and 3 is depicted. Analysis of the consumption ratios from Preference Test 1 and Day 1 of Preference Sessions 2 and 3 failed to yield any significant effects [largest $F(2,34)=.40$ ]. Additionally, separate analyses of the consumption scores over the four daily tests of Preference Sessions 2 and 3 failed to yield significant effects [largest $F(3,51)=.25$ ] .

Analysis of the saccharin-consumption data from the 4-day saccharin-extinction phase yielded significance for the groups $[F(1,17)=7.267, p=.014]$ and days $[F(3,51)$ $=66.77, p<.001]$ effects. Newman-Keuls tests indicated that significantly more saccharin was consumed on Day 4 than on Day $1(p<.01)$. Moreover, the Grits animals consumed significantly more saccharin than did the Normal animals $(p<.01)$.

An analysis of the consumption ratios from the final test (Day 4) of Preference Session 3 with those of Preference Test 4 yielded significance for the days factor $[F(1,17)=44.06, p<.001]$. Thus, although the groups did not differ reliably, the 4 days of saccharin extinction effectively attenuated the saccharin aversion.

\section{DISCUSSION}

Two major conclusions are suggested by the present data. First, the weight differential that developed between the two groups during the grits-exposure phase corroborate the Remley et al. (1980) and Becker et al. (1989) reports. Clearly, the protein- and tryptophan-deficient grits diet suppressed growth and weight gain significantly. However, the weight gains shown by the Grits subjects following the switch to the regular diet indicated that this differential is reversible. The latter result also corroborates the Becker et al. (1989) report.

Second, the taste-aversion data indicate that the 50-day exposure to the experimental grits diet failed to produce permanent effects that impacted upon the acquisition of this basic, classically conditioned response. Moreover, the conditioned aversion was equally robust in long-term retention tests and equally resistant to extinction in both normally reared and experimental animals. These results are in accord with previous reports indicating that exposure to a deficient diet of this nature did not result in decreased learning capacity.

Although it is arguable that the Grits animals may not have received sufficient exposure to the experimental diet to produce discernible effects, this possibility seems unlikely. In the present study, the experimental diet was administered from weaning (21 days) until maturity (71 days). Had the exposure been started earlier, the possibility of mortality would have to be dealt with (see Becker et al., 1989). Hence, the only viable possibility would be to maintain the animals on the grits diet for a longer period of time. Although it seems unlikely that extending this exposure beyond maturity would produce significant effects, this option certainly is testable.

\section{REFERENCES}

Becker, A. H., Davis, S. F., Grover, C. A., \& Erickson, C. A. (1989). The effects of a tryptophan- and protein-deficient diet upon growth in rats. Bulletin of the Psychonomic Society, 27, 345-347.

Becker, A. H., Davis, S. F., Grover, C. A., Erickson, C. A. (Eds.) (1990). Effects of a protein- and tryptophan-deficient diet upon complex maze performance. Bulletin of the Psychonomic Society, 28, 126-128. BEST, M. R. (1975). Conditioned and latent inhibition in taste-aversion learning: Clarifying the role of learned safety. Journal of Experimental Psychology: Animal Behavior Processes, 1, 97-113. 
Caldwell, D. F., \& Churchill, J. A. (1967). Learning ability in the progeny of rats administered a protein-deficient diet during the second half of gestation. Neurology, 17, 95-99.

Cowley, J. J., \& Griesel, R. D. (1959). Some effects of a low protein diet on a first filial generation of white rats. Journal of Genetic Psychology, 95, 187-201.

Cowley, J. J., \& Griesel, R. D. (1963). The development of secondgeneration low-protein rats. Journal of Genetic Psychology, 103, 233-242.

Cravioto, J., \& Robles, B. (1965). Evolution of adaptive and motor behavior during rehabilitation from kwashiorkor. American Journal of Orthopsychiatry, 35, 449-464.

Dragoin, W., McCleary, G. E., \& McCleary, P. (1971). A comparison of two methods of measuring conditioned taste aversions. Behavior Research Methods \& Instrumentation, 3, 309-310.

Garcia, J., Hankins, W. G., \& RusiniaK, K. W. (1974). Behavioral regulation of the milieu interne in man and rat. Science, 185, 824-831.

KALAT, J. W. (1974). Taste salience depends on novelty, not concen- tration, in taste-aversion learning in the rat. Journal of Comparative \& Physiological Psychology, 86, 47-50.

Kaplan, B. J. (1972). Malnutrition and mental deficiency. Psychological Bulletin, 78, 321-334.

Remley, N. R., Armstrong, D. R., Gilman, D. P., \& Mercer, L. F., JR. (1980). Effects of early protein malnutrition on learning in the rat. Bulletin of the Psychonomic Society, 16, 377-379.

WINICK, M. (1976). Malnutrition and brain development. London: Oxford University Press.

\section{NOTES}

1. One of the males in the Grits group died during the gritsexposure phase. Therefore, unweighted means analyses were employed in all instances.

(Manuscript received May 5, 1990.) 